\title{
Variations in the total electron content near the crest of the equatorial ionization anomaly during the November 2004 geomagnetic storm
}

\author{
Nirvikar Dashora and R. Pandey \\ Department of Physics, M. L. S. University, Udaipur 313 001, India
}

(Received August 16, 2005; Revised October 8, 2006; Accepted October 10, 2006; Online published March 21, 2007)

\begin{abstract}
Space weather studies using a Global Positioning System (GPS) receiver are underway near the crest of the equatorial ionization anomaly (EIA), at Udaipur (MLAT $16.0^{\circ} \mathrm{N}$ ), India. These studies are probably, the first of its kind in the Indian zone near the crest of the EIA. Results for the geomagnetic storm that occurred during November 2004 are presented. Drastic variations in the total electron content (TEC) have been observed as a result of this storm. It is inferred that the reduced levels of TEC following the storm may be attributed to the weakened equatorial plasma fountain due to the disturbance dynamo fields.
\end{abstract}

Key words: Space weather, Global Positioning System (GPS), geomagnetic storms, total electron content (TEC), equatorial ionization anomaly (EIA).

\section{Introduction}

The southward turning of the $\mathrm{z}$-component of the interplanetary magnetic field (IMF $B_{z}$ ) has dramatic effects on the topology of the ionospheric plasma. It is one of the key parameters that characterize the onset of a geomagnetic storm. At the magnetospheric heights, the geomagnetic field is northward. A southward IMF $B_{z}$ is thus needed to open the Earth's closed dayside magnetic field to the solar wind. The anti-sunward magnetospheric convection is produced when the reconnected, open field lines are swept over the polar caps at the solar wind speed. The dawn-todusk solar wind electric field thus maps along the field lines to the tail side magnetosphere. The interaction of the solar wind, magnetosphere, thermosphere and the ionosphere is very complex. Studies of storm time ionospheric electrodynamics have revealed the occurrence of large electric fields and currents during and after geomagnetically disturbed periods (e.g. Fejer and Scherliess, 1995). The disturbance electric fields at the low latitudes have been identified as prompt penetration zonal electric fields and the disturbance dynamo electric fields. The prompt penetration fields are produced both during the southward turning of the IMF $B_{z}$ (Fejer et al., 1979; Fejer, 1986; Sastri et al., 1992) and also during the terminating phase of the substorm when the IMF $B_{z}$ turns northward (Gonzales et al., 1979; Kelley et al., 1979; Spiro et al., 1988; Abdu et al., 2003). The disturbance dynamo fields are produced due to the increased corpuscular radiation and consequent Joule heating of the high latitude plasma. This additional heating may launch equatorward winds, which in turn generate disturbance dynamo fields (e.g. Blanc and Richmond, 1980; Scherliess and Fejer, 1997). In addition, Fuller-Rowell et al. (2002) have

Copyright (c) The Society of Geomagnetism and Earth, Planetary and Space Sciences (SGEPSS); The Seismological Society of Japan; The Volcanological Society of Japan; The Geodetic Society of Japan; The Japanese Society for Planetary Sciences; TERRAPUB. shown that the mid-latitude storm time winds, which may be forced in the very early stages of the storm, may drive an F-region dynamo. The resultant electric fields leak immediately to the equator. The mechanism for the generation of the field given by Fuller-Rowell et al. (2002) is different from that of Blanc and Richmond (1980). The prompt penetration fields are transmitted to the low latitudes on the time scales of an hour or so (e.g., Fejer, 2002), whereas the time scales associated with the transmission of the disturbance dynamo fields are much longer (e.g., Scherliess and Fejer, 1997). The delayed effects of solar disturbances on the ionospheric plasma density are manifested on time scales of several hours to days.

These disturbance electric fields may lead to the redistribution of ionospheric plasma. Drastic changes in ionospheric vertical total electron content (VTEC) can also be produced by intense disturbance electric fields originating from the magnetosphere-ionosphere interaction (e.g., Tsurutani et al., 2004). The process could also lead to a significant modification of the TEC at low and mid latitudes (e.g. Fuller-Rowell et al., 1997). In recent years, a number of workers have used Global Positioning System (GPS) receivers to assess the impact of the geomagnetic storms on the TEC at various latitudes (e.g., Jakowaski et al., 1999; Tsugawa et al., 2003; Zhang and Xiao, 2003; Biktash, 2004; Maruyama et al., 2004; Kutiev et al., 2005; Mitchell et al., 2005; Zhao et al., 2005). These studies over the EIA zone are especially important because the equatorial plasma fountain is highly sensitive to the disturbance electric fields. Udaipur (in India) is situated (Geog. Lat. 24.6 $\mathrm{N}$, Geog. Long. $73.7^{\circ} \mathrm{E}$, MLAT $16.0^{\circ} \mathrm{N}$ ) near the crest of the EIA and, therefore, is a very appropriate location for the space weather studies. This has been the motivation for initiating the TEC measurements using a GPS receiver at Udaipur. The TEC variations obtained using a GPS receiver during the November 2004 geomagnetic storm have been studied. 


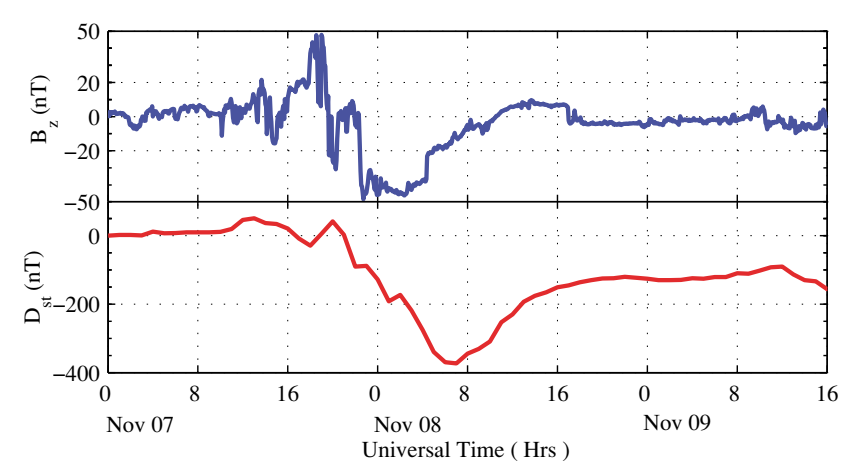

Fig. 1. Variation in the IMF $B_{z}$ (upper panel) and $D_{s t}$ index (lower panel) during November 07-November 09, 2004. The lowest value of IMF $B_{z}$ was about $-50 \mathrm{nT}$ around $2200 \mathrm{UT}$ on November 07 . The lowest value of the $D_{s t}$ index was $-373 \mathrm{nT}$ at $0700 \mathrm{UT}$ on November 08 .

The storm time variations of the TEC, derived using a GPS receiver, are presented for the first time from the Indian EIA zone.

\section{Observations}

\subsection{Geomagnetic conditions}

The Sun was moderately active during the period November 03-11, 2004, with a number of solar flares occurring during this period. All of the flares originated from a single active region, with NOAA number 10696. In this paper we present the results pertaining to the geomagnetic storm of November 07-08, 2004. Figure 1 presents the variations in the IMF $B_{z}$ and the $D_{s t}$ index for the period November 07-09, 2004. The variations in the IMF $B_{z}$ were very complex on November 07 . The IMF $B_{z}$ turned southward for a very short duration around 1430 UT and recovered thereafter to become northward by about 1500 UT. It remained northward with a peak value of about $+47 \mathrm{nT}$, and after 1930 UT it turned southward. It remained southward up to about 2024 UT. It fluctuated between the north and south directions from about 2024 UT (universal time) to 2200 UT. Thereafter, it remained southward with an average value of about $-40 \mathrm{nT}$ up to about 0416 UT on November 08 . Thereafter it recovered gradually. By 1028 UT on November 08 , the value of IMF $B_{z}$ was around $0 \mathrm{nT}$. The corresponding $D_{s t}$ variations are shown in the lower panel of Fig. 1. The major storm sudden commencement (SSC) occurred around 1930 UT on November 07 , and the $D_{s t}$ index dropped to a value of $-373 \mathrm{nT}$ at $0700 \mathrm{UT}$ on November 08 . The $D_{s t}$ index recovered thereafter, and by the midnight of November 08 its value was $-126 \mathrm{nT}$.

\subsection{Ionogram data}

Variations in the ionospheric parameters, namely, the virtual height of the F layer $\left(h^{\prime} F\right)$ and the ionospheric critical frequency of the $\mathrm{F}$ layer ( $f o F 2$ ), for an Indian equatorial station, Thumba geomagnetic latitude (MLAT): $0.43^{\circ} \mathrm{S}$, are shown in Fig. 2. The ionograms were scaled for a quiet day on November 06 and for the storm day on November 08 . The left panels in Fig. 2 show the variations in the $h^{\prime} F$ on these two days. The right panels show the variations in the $f o F 2$. The lower abscissa in Fig. 2 is the Indian Standard Time (IST $=\mathrm{UT}+05: 30 \mathrm{hr}$ ), and the top abscissa gives the time in UT. Variations in $h^{\prime} F$ and $f o F 2$ on Novem-
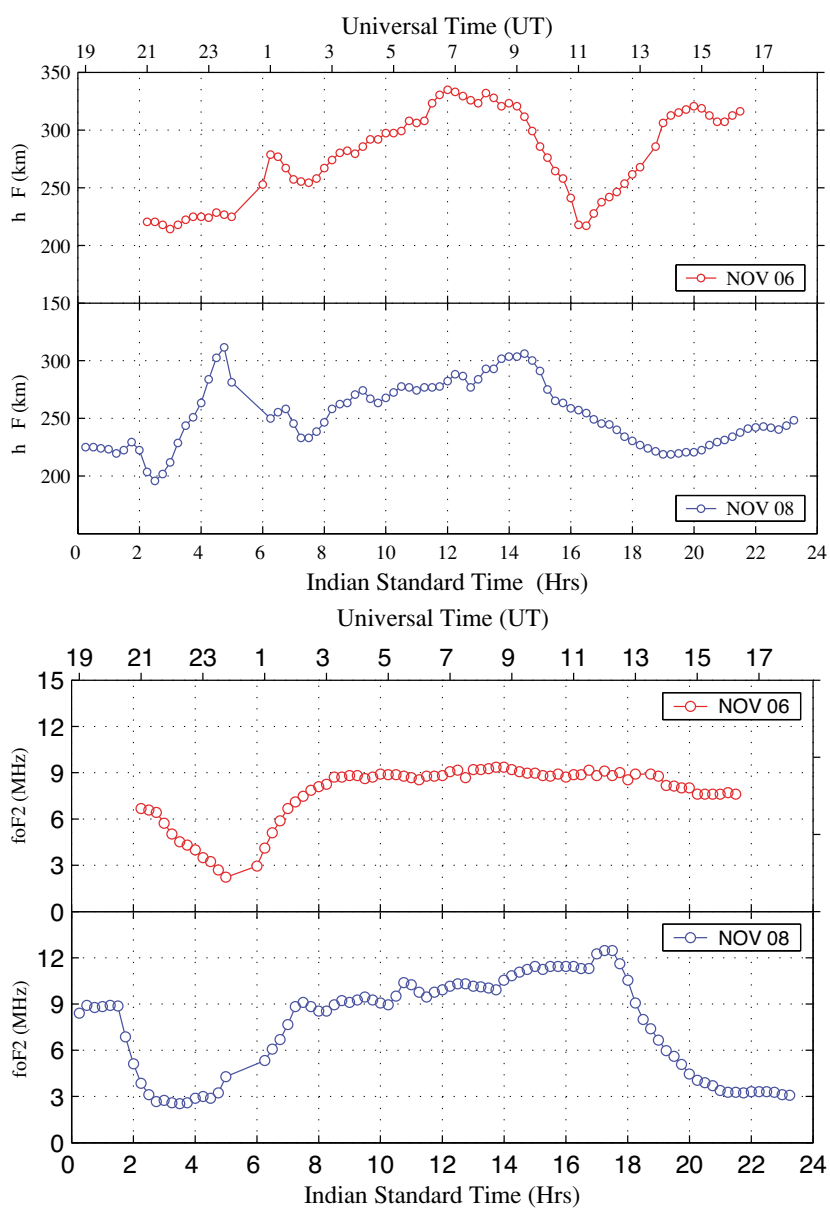

Fig. 2. Variation in $h^{\prime} f$ (left panels) and $f o F 2$ (right panels) on November 06 (upper panels) and November 08 (lower panels), 2004. The top abscissa gives the corresponding time in universal time (UT).

ber 06 are in conformity with the diurnal variations of these parameters on a quiet day. It can be seen from Fig. 2 that after sunrise on November 06 , the $h^{\prime} F$ increased, attaining a maximum level of $340 \mathrm{~km}$ by 12:00 hours. Thereafter, it decreased continuously up to about $16: 30$ hours, reaching its evening minimum level of about $210 \mathrm{~km}$, In contrast, the foF 2 increased rapidly and attained a level of about $9 \mathrm{MHz}$ by about 09:00 hours, remaining almost the same throughout. After 21:30 hours, the ionograms could not be scaled due to the occurrence of the spread-F. The bottom panels show the variations in the $h^{\prime} f$ and the $f o F 2$ on November 08 , which are quite different from the November 06 variations. During the daytime on November 08, the $h^{\prime} F$ slowly increased after 07:00 hours and reached a height of about $300 \mathrm{~km}$ at 14:30 hours. Thereafter, the F layer came down gradually and reached a minimum level of about $210 \mathrm{~km}$ around 19:00 hours. Hence, on November 08 the maximum height of the $\mathrm{F}$ layer during the daytime was lower by about $40 \mathrm{~km}$ compared to that on November 06 . In terms of the variations of $f o F 2$ on November 08 , immediately after the sunrise it increased rapidly and reached a value of about 9 $\mathrm{MHz}$ by about 08:00 hours. A slow increasing trend persisted thereafter and by about 18:00 hours, its value was $12 \mathrm{MHz}$. Thereafter, the $f o F 2$ declined sharply and was 3 $\mathrm{MHz}$ by 21:00 hours. Thus, it is evident from Fig. 2 that 

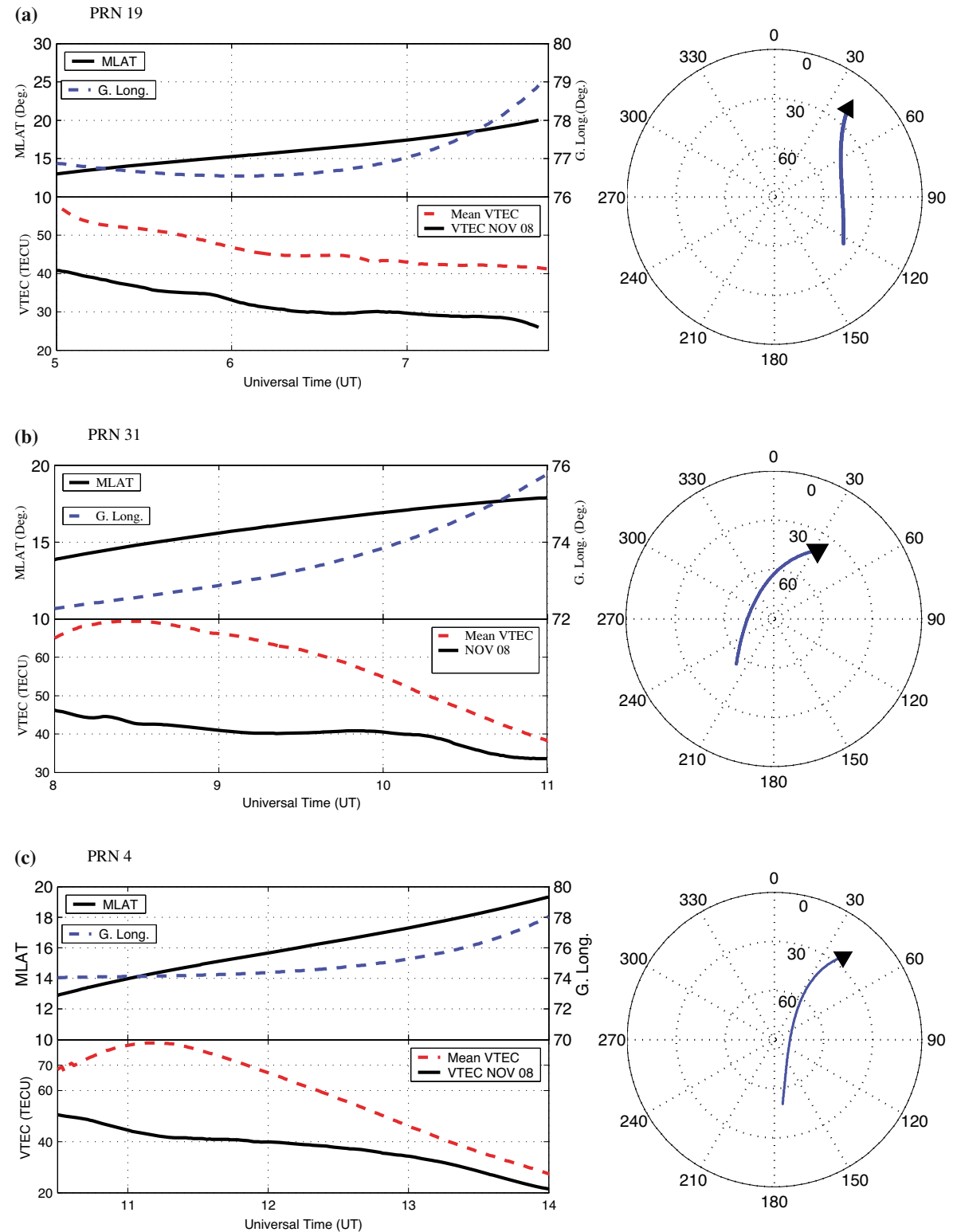

Fig. 3. Variation in the VTEC (lower panels), the geomagnetic latitude (MLAT) and geographic longitude of the IPP (upper panels) against UT for the satellites with PRNs 19, 31 and 4 respectively. The storm time VTEC (continuous curve) is compared with the mean VTEC (broken curve). A polar plot giving the azimuth-elevation of each PRN at each instant of time is shown in the right panels. The arrow indicates the direction of the satellite pass and its length indicates the duration for which the data are presented.

the maximum height of the $\mathrm{F}$ layer at the equator was substantially lower during the daytime on November 08, than on the normal day, whereas the $f o F 2$ values were larger by about 2-3 MHz. The larger values of $f o F 2$ on November 08 imply higher levels of electron density prevailing at the lower levels.

\subsection{GPS TEC data}

The GPS receiver provides the slant TEC along the line of sight between the receiver and a given satellite. These measurements are corrupted due to the receiver bias and the satellite bias errors and, consequently, the errors have to be estimated and removed during the post-processing of the data (Ma and Maruyama, 2003). Since these errors are known to vary over periods of weeks to months, for studies over a shorter duration of about 1 week or so, these may be assumed to be constant. However, the magnitude of the satellite bias errors would not be the same for different satellites. In the present studies, these errors have not been removed completely. However, they do not pose a serious threat in the present case as we are interested in comparing the storm time TEC values with the quiet time TEC immediately preceding the storm. The slant TEC provided by the receiver has been converted into the vertical TEC (VTEC) following the procedure of Ma and Maruyama (2003). For this, a thin ionospheric shell at an altitude of $350 \mathrm{~km}$ has been assumed. The VTEC thus calculated corresponds to the coordinates of the ionospheric pierce point (IPP) at each instant of time. The GPS satellites are designated by a pseudo-random number (PRN). Accordingly, the results for the satellites with PRNs 19, 31 and 4 are presented in Fig. 3(a), (b) and (c), respectively. These PRNs are so chosen as to cover the whole day of November 08, 2004. In 
each of these figures, variations in the VTEC, the MLAT and geographic longitude of the IPP are plotted against the UT. Further, the VTEC on November 08, following the storm, is compared with the mean VTEC, which has been computed using data from 7 quiet days preceding the storm. In order to mitigate the effect of multipath, the data for only that part of each satellite pass has been chosen for which its elevation was more than $30^{\circ}$. A polar (azimuth-elevation) plot of the satellite pass, as seen over Udaipur, is also shown to the right of Fig. 3(a)-(c). The concentric circles are separated by $30^{\circ}$ each, designated by decreasing elevation from the center. The center denotes the overhead position of the satellite. Thus, the polar plot provides the pictorial view of the location of the satellite vis-à-vis the location of the receiver (Udaipur).

Figure 3(a) gives the results for the PRN 19 during its pass between 05:00 UT to about 08:00 UT. The variations in the MLAT and the geographic longitude of the IPP are plotted in the upper panel of this figure. Variation of the IPP coordinates has been shown to indicate the position of the satellite vis-à-vis the geomagnetic equator. The curve drawn with a solid line is for the MLAT (left ordinate), and the broken line curve is for the longitude (right ordinate) of the IPP. The MLAT of the IPP varies from about $13^{\circ}$ to $20^{\circ}$, whereas its longitude varies from about $76^{\circ}$ to $79^{\circ}$. It is evident from the lower panel of Fig. 3(a) that the VTEC on November 08 is lower by about 15 TECU compared to the mean VTEC between 0500 UT and 0800 UT. The VTEC on November 08 was also consistently lower than the mean VTEC between 0800 UT and 1100 UT (Fig. 3(b)). The mean VTEC for this pass declines as the satellite moves away from the anomaly crest. The maximum difference is 25 TECU around $0830 \mathrm{UT}$, reducing to about 5 TECU at 1100 UT. Figure 3(c), which is for the period from about 1030 UT to $1400 \mathrm{UT}$, also reveals similar variations in the VTEC on November 08. Here also, the mean VTEC values are higher than on November 08. It may be noted that 1400 UT corresponds to the 19:30 hours of local evening. It is evident from Fig. 3(a)-(c) that, on November 08, the VTEC was much lower than the quiet time mean VTEC. The variability in the difference of the two VTECs is due to the fact that the VTEC depends both on the local time and the latitude and longitude of a location. We attribute the reduction in TEC on November 08, compared to the mean VTEC, to the disturbance dynamo fields, which damped the development of the EIA.

\section{Discussion}

The plasma density in the anomaly zone latitudes is known to depend on the direction and strength of the electric field at the equator. During geomagnetic storms, the equatorial electric fields are drastically affected (Fejer and Scherliess, 1995). Since the TEC is the line of sightintegrated plasma density, any variations in the plasma density are likely to be reflected in the TEC. There are a number of studies describing the effect of geomagnetic storms on the TEC, measured using the GPS receivers (e.g. Tsugawa et al., 2003; Maruyama et al., 2004; Tsurutani et al., 2004; Kutiev et al., 2005; Zhao et al., 2005). As has been noted earlier, the storm time electric fields are of two types, namely, the prompt penetration fields and the disturbance dynamo fields. Convection of the prompt penetration fields from high latitudes to low latitudes typically takes about an hour or so (Fejer and Scherliess, 1995).

The disturbance dynamo fields are associated with the enhanced energy deposition into the high latitude ionosphere during geomagnetically active periods (Blanc and Richmond, 1980). Their effect on the ionosphere may be felt over the time periods of several hours to days after the geomagnetic storms. The disturbance dynamo field at the equator is westward during the day and eastward during the night (Zhao et al., 2005), whereas the direction of the zonal ambient electric field is eastward during the day and westward during the night. Hence, these two types of fields are oppositely directed. The disturbance fields produce remarkable effects in the equatorial ionosphere as the $\mathbf{E} \times \mathbf{B}$ vertical plasma drift is severely affected. As a result, the fountain effect may be modified considerably, leading to the redistribution of plasma in the anomaly zone latitudes.

At the time of the southward turning of the IMF $B_{z}$ on November 07 , the corresponding local time at the equator in the Indian zone was nighttime. However, from our data, we could not detect the effect of the prompt penetration electric field on the TEC.

As has been inferred from Fig. 3, the TEC values during the daytime on November 08 were far lower than the mean TEC for the quiet days. These observations correspond to a period of about $12 \mathrm{~h}$ into the storm. Scherliess and Fejer (1997) have noted that there is a complex interplay of disturbance dynamo electric fields at different time scales and a large variability in the efficiencies of the different dynamo processes. The short-term disturbance dynamo, as characterized by time delays of 1-12 h, generates upward vertical velocities at night and smaller downward velocities during the day at the equator. Therefore, the resultant daytime upward plasma velocity at the equator would decrease. This is evident from the lower height of the F layer on November 08 (Fig. 2). Since the height of the F layer was lower, the plasma fountain was damped. Hence, it may be concluded that the weakened plasma fountain effect could not lift the plasma to sufficiently high altitudes so as to diffuse the plasma along the field lines to anomaly zone latitudes. As a result, the ionization anomaly could not develop sufficiently. Compared to the normal day, this would result in lower TEC values near the crest of the anomaly, as observed on November 08 .

Acknowledgments. The GSV 4004A receiver was purchased through the grants from the University Grants Commission, New Delhi under the DRS-SAP, and X plan. The work is partially supported under the ISRO-RESPOND program. Authors are thankful to the Director, Space Physics Laboratory, VSSC, Trivendrum, India for providing the ionogram data. The data for the $D_{s t}$ index was downloaded from World Data Centre for Geomagnetism, Kyoto. The IMF $B_{z}$ data was taken from the site http://www.srl.caltech.edu/ACE/index.html.

\section{References}

Abdu, M. A., I. S. Batista, H. Takahashi, J. MacDougall, J. H. A. Sobral, A. F. Medeiros, and N. B. Trivedi, Magnetospheric disturbances induced equatorial plasma bubble development and dynamics, J. Geophys. Res., 108(A12), 1449, 2003. 
Blanc, M. and A. D. Richmond, The ionospheric disturbance dynamo, $J$. Geophys. Res., 85, 1669-1686, 1980.

Biktash, L. Z., Role of magnetospheric and ionospheric currents in the generation of equatorial scintillations during geomagnetic storms, Ann. Geophys., 22, 3195, 2004.

Fejer, B. G., Equatorial ionospheric electric fields associated with magnetospheric disturbances, in Solar Wind Magnetospheric Coupling, edited by Y. Kamide and J. A. Slavin, Terra Sci., Tokyo, 519-545, 1986.

Fejer, B. G., Low latitude storm time ionospheric electrodynamics, $J$. Atmos. Sol. Terr. Phys., 64, 1401-1408, 2002.

Fejer, B. G., C. A. Gonzalez, D. T. Farley, and M. C. Kelley, Equatorial electric fields during magnetically disturbed conditions, J. Geophys. Res., 84, 5797-5802, 1979.

Fejer, B. G. and L. Scherliess, Time dependent response of equatorial ionospheric electric fields to megnetospheric disturbances, Geophys. Res. Lett., 22, 851-854, 1995.

Fuller-Rowell, T. M., M. V. Codrescu, R. G. Roble, and A. J. Richmond, How does the thermosphere and ionosphere react to a geomagnetic storm?, in Magnetic Storm, Geophys. Monogr. Ser., 98, edited by B. T. Tsurutani et al., 203, AGU, Washington, D. C., 1997.

Fuller-Rowell, T. M., G. H. Miillward, A. D. Richmond, and M. V. Codrescu, Storm-time changes in the upper atmosphere at low latitudes, $J$. Atmos. Sol. Terr. Phys., 64, 1383-1391, 2002.

Gonzalez, C. A., M. C. Kelly, B. G. Fejer, J. F. Vickrey, and R. F. Woodman, Equatorial electric fileds during magnetically disturbed conditions, 2, Implication of simultaneous auroral and equatorial measurements, $J$. Geophys. Res., 84, 5803-5812, 1979.

Jakowaski, N., S. Schluter, and E. Sardon, Total electron content of the ionosphere during the geomagnetic storm on 10 January 1997, J. Atmos. Terr. Phys., 61, 299-307, 1999.

Kelly, M. C., B. G. Fejer, and C. A. Gonzalez, An explanation for anomalous equatorial ionospheric electric fields associated with the northward turning of the interplanetary magnetic field, Geophys. Res. Lett., 6, 301, 1979.

Kutiev, I., S. Watanabe, Y. Otsuka, and A. Saito, Total electron content behavior over Japan during geomagnetic storms, J. Geophys. Res., 110, A01308, 2005.
Ma, G. and T. Maruyama, Derivation of TEC and estimation of instrumental biases from GEONET in Japan, Ann. Geophys., 21, 2083-2093, 2003.

Maruyama, T., G. Ma, and M. Nakamura, Signature of TEC storm on 6 November 2001 derived from dense GPS receiver network and ionosonde chain over Japan, J. Geophys. Res., 109, A10302, 2004.

Mitchell, C. N., L. Alfonsi, G. De Franceschi, M. Lester, V. Romano, and A. W. Wernik, GPS TEC and scintillation measurements from the polar ionosphere during the October 2003 storm, Geophys. Res. Lett., 32, L12S03, 2005.

Sastri, J. H., K. B. Ramesh, and H. N. Rangnath Rao, Transient composite electric field disturbances near dip equator associated with auroral substorms, Geophys. Res. Lett., 19, 1451-1454, 1992.

Scherliess, L. and B. G. Fejer, Storm time dependence of equatorial disturbance dynamo zonal electric field, J. Geophys. Res., 102, 24037-24046, 1997.

Spiro, R. W., R. A. Wolf, and B. G. Fejer, Penetration of high latitude electric field effects to low latitudes during SUNDIAL 1984, Ann. Geophys., 6, 39-50, 1988.

Tsugawa, T. A., Y. Saito, Y. Otsuka, and M. Yamamoto, Damping of largescale traveling disturbances with GPS networks during the geomagnetic storm, J. Geophys. Res., 108(A3), 1127, 2003.

Tsurutani, B., A. Manucci, B. Iijima, M. A. Abdu, J. H. A. Sobral, W. Gonzalez, F. Guarnier, T. Tsuda, A. Saito, K. Yumoto, B. G. Fejer, T. J. Fuller-Rowell, J. Kozyra, J. C. Foster, A. Coster, and V. M. Vasyliunas, Global dayside ionosphere uplift and enhancement associated with interplanetary electric field, J. Geophys. Res., 109, A08302, 2004.

Zhang, D. H. and Z. Xiao, Study of ionospheric total electron content response to the great flare on 15 April 2001 using the International GPS Service network for the whole sunlit Hemisphere, J. Geophys. Res., 108(A8), 2003.

Zhao, B., W. Wan, and L. Liu, Responses of equatorial anomaly to the October-November 2003 superstorms, Ann. Geophys., 23, 693, 2005.

N. Dashora and R. Pandey (e-mail: pandey_r@yahoo.com) 